\title{
Ovarian cancer: epigenetics, drug resistance, and progression
}

\author{
Weiwei Xie ${ }^{1 \dagger}$, Huizhen Sun ${ }^{1 \dagger}$, Xiaoduan $\mathrm{Li}^{2}$, Feikai Lin ${ }^{1}$, Ziliang Wang ${ }^{1 *}$ and Xipeng Wang ${ }^{1 *}$ (D)
}

\begin{abstract}
Ovarian cancer (OC) is one of the most common malignant tumors in women. $\mathrm{OC}$ is associated with the activation of oncogenes, the inactivation of tumor suppressor genes, and the activation of abnormal cell signaling pathways. Moreover, epigenetic processes have been found to play an important role in OC tumorigenesis. Epigenetic processes do not change DNA sequences but regulate gene expression through DNA methylation, histone modification, and non-coding RNA. This review comprehensively considers the importance of epigenetics in OC, with a focus on microRNA and long non-coding RNA. These types of RNA are promising molecular markers and therapeutic targets that may support precision medicine in OC. DNA methylation inhibitors and histone deacetylase inhibitors may be useful for such targeting, with a possible novel approach combining these two therapies. Currently, the clinical application of such epigenetic approaches is limited by multiple obstacles, including the heterogeneity of OC, insufficient sample sizes in reported studies, and non-optimized methods for detecting potential tumor markers. Nonetheless, the application of epigenetic approaches to $\mathrm{OC}$ patient diagnosis, treatment, and prognosis is a promising area for future clinical investigation.
\end{abstract}

Keywords: Epigenetics, Ovarian cancer, MiRNA, LncRNA, DNA methylation, Histone modifications

\section{Background}

Ovarian cancer (OC) is one of the deadliest, most malignant gynecological tumors. Due to its insidious onset, most patients have no specific manifestations or symptoms during the early stages of the disease. The lack of sensitive and efficient clinical screening methodology results in most diagnoses occurring at an advanced stage. Based on the latest statistics from the American Cancer Society, there are approximately 20,000 new cases of OC annually, accounting for $5 \%$ of all female malignant tumors, with a death rate of $62 \%$ [1]. The incidence of $\mathrm{OC}$ is increasing not only in Western countries, but also

*Correspondence: wangziliang@xinhuamed.com.cn; wangxipeng@xinhuamed.com.cn

${ }^{\dagger}$ Weiwei Xie and Huizhen Sun contributed equally to this work ${ }^{1}$ Department of Obstetrics and Gynecology, Shanghai Jiao Tong University School of Medicine Xinhua Hospital, 1665 Kongjiang Road, Yangpu District, Shanghai, China

Full list of author information is available at the end of the article in Asian countries. Approximately $70 \%$ of patients with $\mathrm{OC}$ are diagnosed with advanced disease when the tumor has spread outside of the pelvis and to distant metastatic sites, which cannot be completely removed by surgery. The 5 -year survival rate is $20-30 \%$. The overall OC survival rate could be improved by the identification of specific biomarkers for early diagnosis. This type of discovery would represent a revolutionary breakthrough in OC research.

At present, the pathogenesis and specific etiology of OC are unclear. OC may be due to a combination of genetics, reproductive hormone levels, and behavior. The number of ovulations in a woman's lifetime is proportional to the risk for OC [2]. Among women who are not pregnant, menarche and late menopause result in increased ovulation and are high-risk factors for OC. Protective factors, such as pregnancy, term delivery, lactation, oral contraceptives, and tubal ligation, reduce the occurrence of OC [2]. Genetic factors contribute to approximately $10 \%$ of epithelial ovarian cancer (EOC) [2] original author(s) and the source, provide a link to the Creative Commons licence, and indicate if changes were made. The images or other third party material in this article are included in the article's Creative Commons licence, unless indicated otherwise in a credit line to the material. If material is not included in the article's Creative Commons licence and your intended use is not permitted by statutory regulation or exceeds the permitted use, you will need to obtain permission directly from the copyright holder. To view a copy of this licence, visit http://creativecommons.org/licenses/by/4.0/. The Creative Commons Public Domain Dedication waiver (http://creativeco mmons.org/publicdomain/zero/1.0/) applies to the data made available in this article, unless otherwise stated in a credit line to the data. 
and are usually characterized by the autosomal dominant inheritance of $B R C A 1$ or $B R C A 2$ genetic mutations [3]. The loss of function in genes encoding BRCA proteins results in the instability of tumor suppressors.

$\mathrm{OC}$ was initially thought to originate in the ovaries. With molecular biological analysis, the origin of OC has become controversial [4]. Currently, OC is believed to have three possible origins: ovarian surface epithelium (OSE), fallopian tube, or ectopic endometrial tissue [4, 5]. These tissues have the same embryological origin. According to the cell origin and histological features, OC is classified into epithelial, sex-cord stromal, germ cell and mixed-cell subtypes [6]. EOC is the most common cause of mortality in women with gynecologic tumors, accounting for $85-90 \%$ of all ovarian malignancies [7]. There are four main histologic subtypes of EOC: serous, clear-cell, mucinous, and endometrioid [8]. Fallopian tube cells may be the precursors of the most high-grade serous ovarian cancers (HGSOC) [9], and endometriotic cells may be the precursors of clear-cell and endometrioid tumors [10]. Its heterogeneity is believed to be the main reason for treatment failure and tumor drug resistance [11]. Tumors originating from different anatomical sites may be a possible cause of tumor heterogeneity [4].

Although each subtype has its own molecular and clinical characteristics, treatment for all epithelial ovarian subtypes remains similar, including de-bulking surgery and platinum-based chemotherapy. Regardless of the tissue type, platinum-based chemotherapy is the main treatment of choice for advanced EOC, typically carboplatin combined with paclitaxel [12]. For decades, intrinsic or acquired resistance to chemotherapy in most patients has inevitably posed a major barrier to the successful treatment of OC. Epigenetic drugs comprise a new generation of anticancer drugs that have unique interactions with tumor cells and associated microenvironments. These drugs may be used alone or in combination with classic chemotherapy. The key prognostic factor for OC is the resistance of the patient's tumor to chemotherapy, especially platinum-based drugs. Epigenetic drugs combined with paclitaxel and platinum are more effective than chemotherapy alone [13].

\section{Epigenetics}

Without changing the DNA sequence, epigenetic processes influence the expression and function of genes, which may result in heritable phenotypes [14] (Fig. 1). Epigenetics serves as an adjunct to classical genetics, and epigenetic modifications are significantly influenced by changes in the internal and external environment, playing an important regulatory role in the transgenerational inheritance of acquired traits, fate of stem cells, and occurrence of cancer [15]. This article reviews recent evidence on $\mathrm{OC}$, including occurrence and development, chemotherapy resistance, and the influence of epigenetic processes mediated by non-coding RNA (ncRNA), DNA methylation, and histone modification.

In the human genome, $95 \%$ of the DNA sequence does not encode proteins. The types of ncRNAs include ribosomal RNA (rRNA), transfer RNA (tRNA), microRNA (miRNA), long non-coding RNA (lncRNA), small nuclear RNA (snRNA), small nucleolar RNA (snoRNA), RNA interference (RNAi), small non-coding RNA (sncRNA), and short interfering RNA (siRNA) [16]. The importance of ncRNAs was not widely recognized until recently. Although ncRNAs cannot encode proteins, they have specific biological functions, such as the processing and modification of RNA, stabilization of mRNA, regulation of cell translation levels, transport of proteins, and chromatin structural modification [17].

MiRNA is an endogenous non-coding small molecule RNA with a length of 19-25 base pairs (bp), which is formed from its precursor RNA after cleavage by the Drosha and Dicer enzymes. Mature miRNA hinders translation extension by binding to the 3'UTR of target mRNA or by degrading RNA by promoting the separation of ribosomes and mRNA, thereby inhibiting gene expression [18] (Fig. 2). Nearly half of miRNA genes are located at fragile sites or chromosomal fragments that are amplified or deleted in human cancers, suggesting that miRNA is closely related to cancer [19].

LncRNA is a subclass of ncRNA sequences with arbitrary lengths composed of more than $200 \mathrm{bp}$ that were once considered "transcriptional noise" in genomic transcription. In recent years, through biotechnology and high-throughput sequencing, the abnormal expression of IncRNAs has been tightly associated with the biological behavior of tumors through epigenetic and posttranscriptional regulation [20] (Fig. 3). Based on their genomic positions relative to protein-coding genes, lncRNAs can be classified into five major categories: sense, antisense, pseudogenes, intergenic, intronic, and bidirectional promoters [21]. The most common epigenetic modifications of lncRNAs in tumors are imprinting loss or methylation changes (hypomethylation and hypermethylation). LncRNAs are involved in the regulation of imprinted gene networks. For example, as a transcriptional regulator, $\mathrm{H} 19$ regulates tumor growth by transfecting a gene imprinting network [22]. LncRNAs recruit chromatin epigenetic modification factors and change the looseness and tightness of chromatin to achieve chromatin remodeling, thereby regulating gene expression [23]. LncRNAs can recruit DNA methyltransferases, leading to either methylation or demethylation [24]. In addition, lncRNAs are involved in epithelial-mesenchymal transformation (EMT) [25] and cell stemness [26]. 


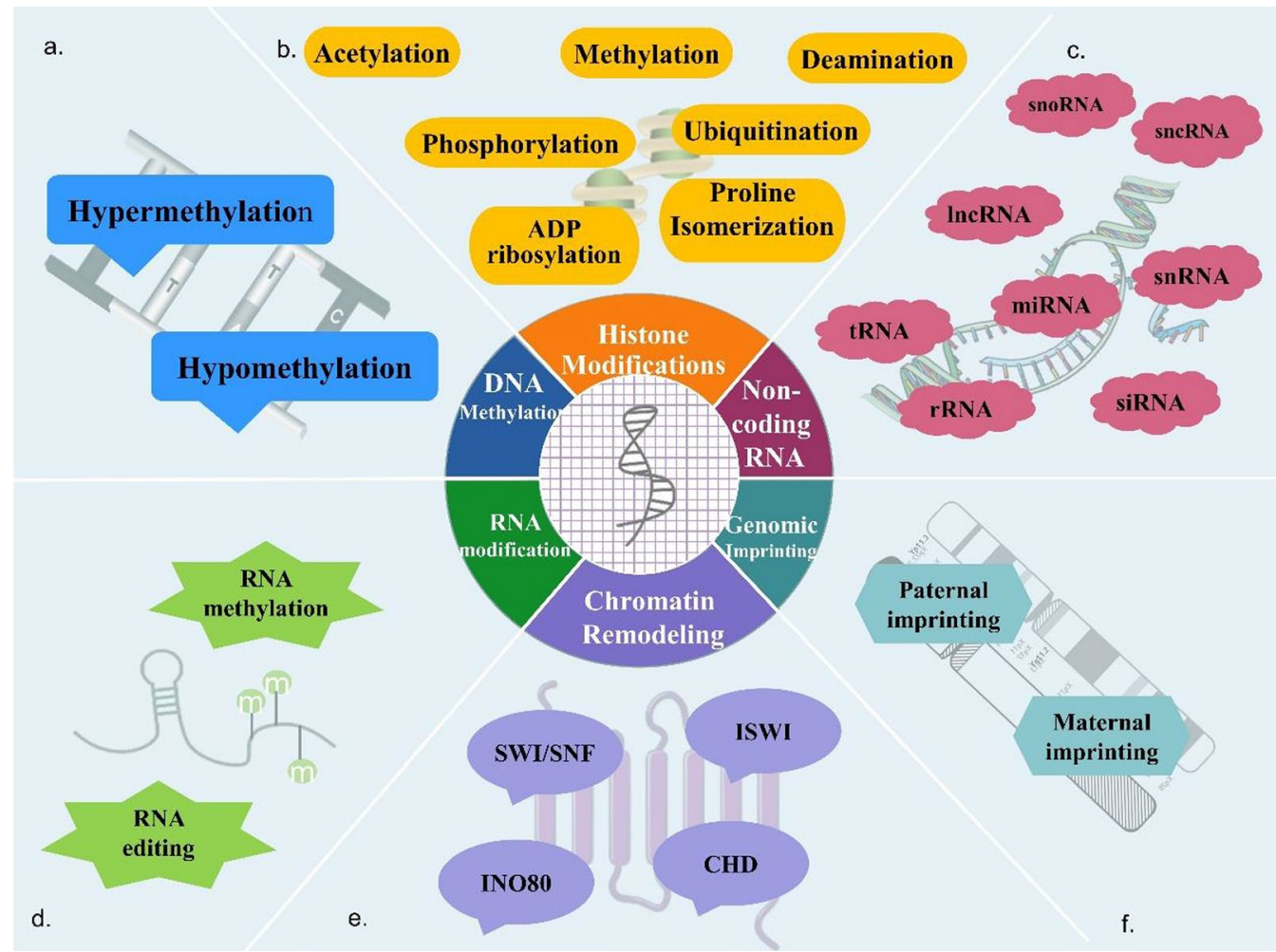

Fig. 1 Epigenetic processes include DNA methylation, histone modification, non-coding RNA, RNA modification, chromatin remodeling, and genomic imprinting. a DNA methylation is divided into two categories: the hypermethylation of CpG islands and global hypomethylation. $\mathbf{b}$ Histone post-translational modifications, including methylation, acetylation, phosphorylation, deamination, ubiquitination, ADP-ribosylation and proline isomerization. c Non-coding RNA including miRNA, IncRNA, rRNA, tRNA, snRNA, snoRNA, sncRNA, siRNA, etc., act in the nucleus or cytoplasm. $\mathbf{d}$ Post-transcriptional modification of RNA through RNA editing and RNA methylation. e Chromatin-remodeling complexes are grouped into four major families: SWI/SNF, INO80, ISWI, and CHD. f Genomic imprinting is an epigenetic process that mainly includes maternal imprinting and paternal imprinting

Interestingly, lncRNAs interact with miRNAs in multiple ways. For example, lncRNAs act as molecular sponges to bind miRNAs and inhibit their binding to mRNA [27]; as precursors of miRNAs, lncRNAs are cleaved by the Dicer enzyme to form mature miRNAs. LncRNAs bind to target miRNAs to promote their degradation, and competition occurs between the two molecules at the same mRNA site [28].

DNA methylation is the most commonly studied epigenetic modification of malignant tumors (Fig. 2). Expressed genes are generally not methylated. In many forms of cancer, tumor suppressor and DNA repair genes are often hypermethylated and silenced. The abnormal methylation of $C p G$ islands (CpG-rich regions, 500$1000 \mathrm{bp}$ in length with GC content exceeding 55\%) can regulate the cell cycle, drug sensitivity, and tumor suppressor gene silencing. The aberrant methylation of DNA changes gene expression, which can promote damage and tumorigenesis [29]. It cannot be ignored that the abnormal methylation of other genomic loci, such as enhancers and repetitive elements, is also the main driving factor for tumor occurrence and development [30]. Furthermore, some evidence suggests that DNA hypomethylation associated with cancer may increase genomic instability [30]. However, promoter DNA methylation does not always act as a transcriptional silencing mechanism. It has been discovered that DNA hypomethylation promotes tumorigenesis through the transcriptional activation of oncogenes [31]. These findings suggest that epigenetics contributes to transcriptional regulation in a more dynamic and complex manner than previously believed.

After histone translation is complete, the amino terminus is covalently modified to regulate the expression of the corresponding gene. Changes in chromatin structure caused by covalent modification are known as ubiquitination, glycosylation, deamination, ADP ribosylation, and proline isomerization [32]. Acetylation and methylation are the two most important modifications that function by upregulating or downregulating gene expression, respectively [33]. Histone modification plays an important role 


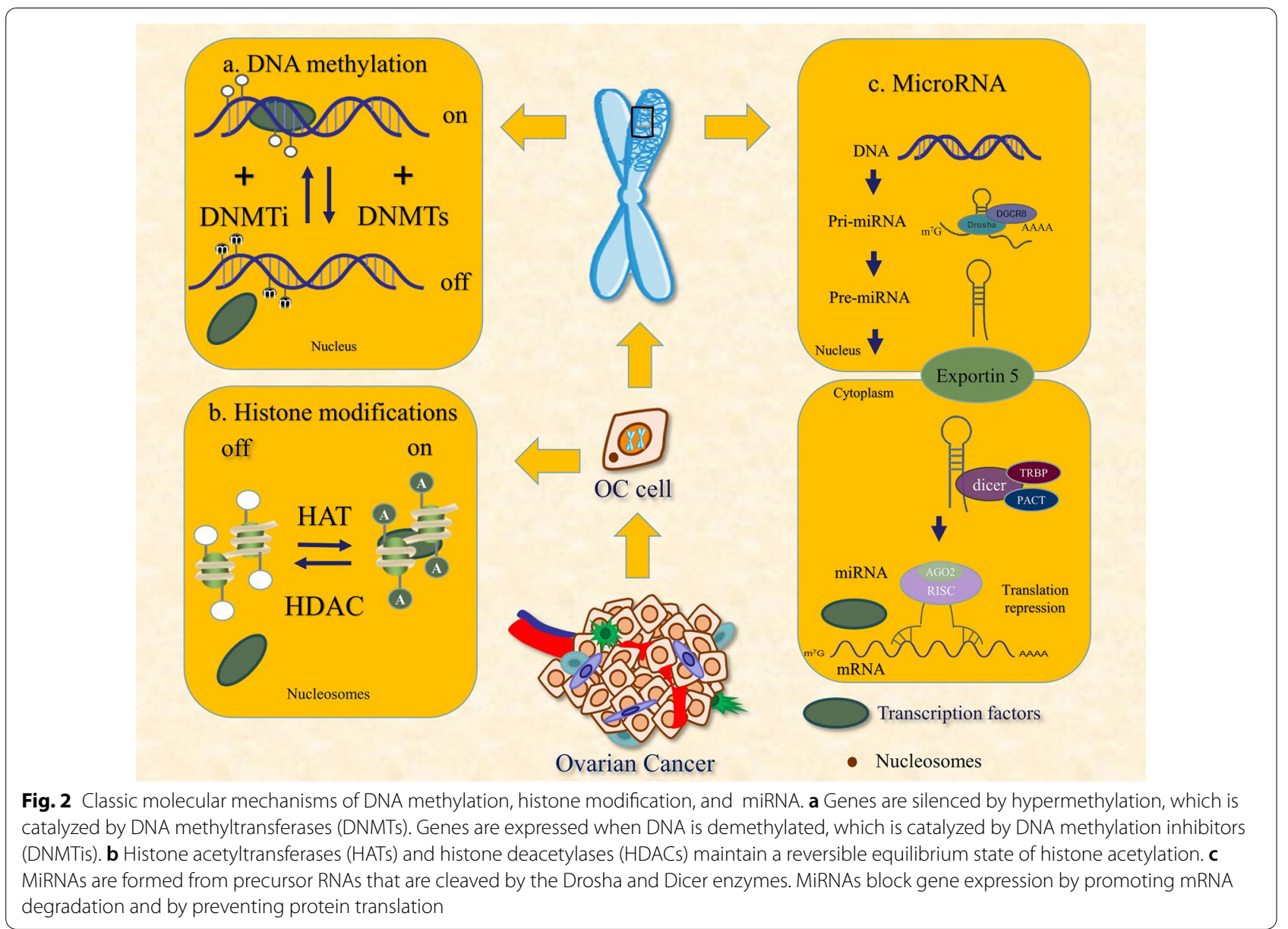

in gene transcription, DNA damage repair, DNA replication, and chromosome condensation [34]. Histone acetyltransferases (HATs) and histone deacetylases (HDACs) maintain a reversible and dynamic equilibrium of histone acetylation (Fig. 2). Histone methylation occurs on lysine or arginine residues of histones $\mathrm{H} 3$ and $\mathrm{H} 4$. The methylation of histone $\mathrm{H} 3$ lysine 27 (H3K27) is related to the silencing of many genes, such as genes imprinted and inactivated on the $\mathrm{X}$ chromosome [35].

In addition, a series of epigenetic modifications have recently been discovered, such as acetylation modifications of RNA, glycation modifications and lactate modifications of histones, whose functions need further exploration. The polycombgroup of proteins (PcG) remodels chromatin and epigenetically silences genes [36].

\section{Application of epigenetics in $O C$ NCRNA in OC MiRNA}

MiRNAs regulate the expression of oncogenes and tumor suppressor genes in OC through a complex circulatory network that controls tumor proliferation, apoptosis, invasion, metastasis, and immune escape [37]. Along with miRNA molecules involved in the pathogenesis of malignant tumors, essential components of miRNA processing (Dicer, Drosha, DGCR8, Argonaut, and TRBP) are also involved [38].

MiRNAs as biomarkers After the miRNA expression profiles of 894 EOC samples were analyzed (the largest collection to date available), 35 miRNAs predicting the risk of progression or relapse were identified. Among them, 16 were associated with a better prognosis, and 19 with a worse prognosis [39]. Due to the enormous number of such reports, this article lists some examples (Table 1). MiRNA is abnormally expressed in different tissue types of $\mathrm{OC}$ and can also be detected in body fluids such as blood, ascites, and urine [40]. Due to effective detection in body fluids, high stability, and tissue-specific expression patterns, miRNAs have potential as novel biomarkers. MiR-34 induces the autophagy and apoptosis of tumor cells, regulates tumor proliferation, and targets notch- 1 , thereby inhibiting cell invasion in OC [41]. Serum miR- 


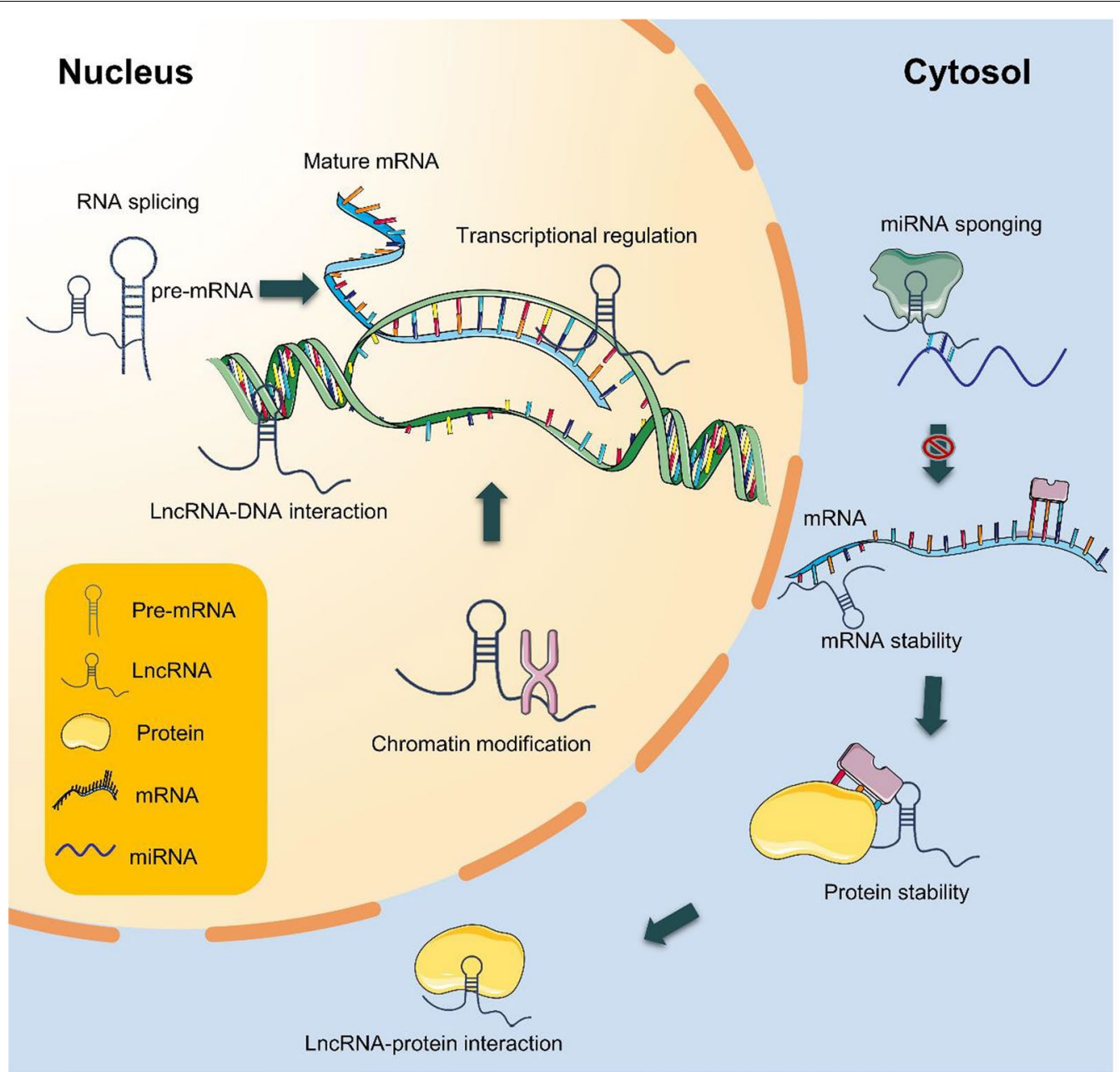

Fig. 3 Schematic mechanisms of IncRNA in regulating gene expression. Nuclear IncRNAs modulate gene expression through chromatin modification, transcriptional regulation, RNA splicing and LncRNA-DNA interaction. In the cytoplasm, IncRNAs play a role in miRNA sponge formation, mRNA stability regulation and protein stability control

Table 1 Expression of miRNA in OC

\begin{tabular}{|c|c|c|c|c|}
\hline Subtype & Up-regulation & Down-regulation & Target/pathway & Reference \\
\hline Serous & miR-9 & & E-cadherin & [43] \\
\hline Epithelial & & miR-219-5p & Twist/Wnt/B-catenin signaling pathway & [44] \\
\hline Serous & miR-616 & & TIMP2 & [130] \\
\hline Hyaline cell & & miR-424 & doublecortin-like kinase 1 & [131] \\
\hline High-grade serous & miR-1290 & & & [132] \\
\hline Epithelial & miR-99a-5p & & fibronectin and vitronectin & [133] \\
\hline Epithelial & miR-1181, miR-4314 & & FOXP1 and GRWD1/IP6K1/NEGR1 & [134] \\
\hline Clear cell and endometriosis & & miR-381 & PIK3CA & [135] \\
\hline Epithelial & & miR-802 & YWHAZ, & [136] \\
\hline Epithelial & & let-7g & c-Myc and cyclin-D2 & [46] \\
\hline Epithelial & & miR-542-3p & CDK14 & [137] \\
\hline
\end{tabular}


375 and miR-1307 are upregulated in OC and may be used to support diagnosis in combination with CA-125 [42]. The overexpression of miR-9 may promote the cell migration and invasion of OC by targeting E-cadherin and become a new potential marker to control the metastasis of OC [43].

While some miRNAs have been suggested to be involved in the proliferation and invasion of $\mathrm{OC}$, others may play opposing roles. MiRNA-219-5p inhibits the invasion, proliferation, and migration of EOC by targeting the Twist/Wnt/ $\beta$-catenin signaling pathway, suggesting its potential role in the diagnosis and treatment of EOC [44]. By targeting multiple oncogenic genes, the classic Let-7 family of miRNAs has a tumor suppressor function. Its expression is downregulated in many cancer cells [45]. Let-7g overexpression induces a significant reduction in OC cancer cell growth. This effect leads to partial arrest of the G0/G1 cell cycle and significant downregulation of c-Myc and cyclin-D2 in OVCAR3 and HEY-A8 cells [46]. The architectural transcription factors HMGA2 and LIN28B and the RNA-binding protein IGF2BP1 form a self-promoting oncogenic "triangle" that adequately antagonizes the tumor inhibitory effects of the let-7 miRNA family [47]. The let-7 antagonistic triangle may be active in a wide range of cancers along with in OC. Impairing the potential of this triangle by targeting let-7 could be a new direction for the diagnosis of early OC. These findings clearly indicate that aberrant expression of miRNAs may serve as novel biomarkers for the diagnosis, prognosis and monitoring of $\mathrm{OC}$.

MiRNAs as therapeutic targets The differential expression of miRNAs is a double-edged sword in OC. Plati- num and paclitaxel are two types of drugs that have been studied in detail to explore the effects of miRNAs on the sensitivity and resistance to chemotherapy in OC. The upregulation or downregulation of specific miRNAs has the potential to modulate the responsiveness of OC cells to chemotherapy (Table 2). Neoadjuvant chemotherapy (NACT) has been recognized as a reliable treatment strategy for patients with advanced EOC. The molecular mechanisms leading to platinum reaction in NACT settings have not been explored. Longitudinal analysis of miRNA expression profiles in HGSOC patients treated with NACT reveals that the expression levels of miR let7G-5p, miR-199a-3p, miR-199a-5p, and miR181a-5p are independently associated with OS and PFS [48]. Moreover, the above-mentioned four miRNAs are correlated with Pt-based resistance and prognosis. Concomitant expression of P-Smad2 and miR181a-5p in surgical samples may be capable of confirming a poor outcome and little chance of response to Pt-based NACT.

MiR-708 increases the sensitivity of cisplatin-resistant cells through the IGF2BP1/Akt pathway [49]. MiR34a downregulates HDAC1 expression while inhibiting proliferation and reducing resistance to cisplatin in OC cells [50]. MiR-136 re-sensitizes OC cells to paclitaxel by targeting the Notch-3 oncogene [51]. The expression of miR-383-5p is downregulated in OC, while the expression of TRIM 27 is upregulated [52]. MiR-383-5p inhibits cell proliferation and enhances paclitaxel chemosensitivity by suppressing TRIM27 expression. Interestingly, oncogenic miR-1246 has been found in $\mathrm{OC}$, and its inhibitor has a significant sensitization effect on paclitaxel [53]. A new mechanism by which miR-503-5p induces metastasis in chemoresistant OC

Table 2 Application of miRNA to OC drug resistance

\begin{tabular}{|c|c|c|c|c|}
\hline miRNA & Resistance against & Function & Target/Pathway & References \\
\hline miR-708 & Cisplatin & Inhibition of metastasis & IGF2BP1/Akt & {$[49]$} \\
\hline miR-136 & Paclitaxel & Inhibition of proliferation & Notch3 & {$[51]$} \\
\hline miR-744-5p & Carboplatin & Promotion of cell apoptosis & NFIX and HNRNPC & {$[138]$} \\
\hline miR-98-5p & cisplatin & Promotion of drug resistance & miR-98-5p/Dicer1/miR-152 & {$[58]$} \\
\hline $\operatorname{miR}-1246$ & Paclitaxel & Promotion of tumor growth & Cav1/p-gp/M2-type macrophage axis & {$[53]$} \\
\hline miR-142-5p & Cisplatin & Inhibition of drug resistance & $\mathrm{XIAP}, \mathrm{BIRC} 3, \mathrm{BCL} 2, \mathrm{BCL} 2 \mathrm{~L} 2$, and MCL1(?) & {$[139]$} \\
\hline miR-509-3p & Platinum & Enhance drug sensitivity & GOLPH3 and WLS & {$[140]$} \\
\hline miR-34a & Cisplatin & Inhibition of proliferation & HDAC 1 & {$[50]$} \\
\hline miR-338-3p & Cisplatin & Inhibition of proliferation, motility, and EMT & WNT2B & {$[141]$} \\
\hline miR-1307 & Paclitaxel & Affects cell cycle dynamics & $\mathrm{ClC}$ & {$[142]$} \\
\hline miR-383-5p & Paclitaxel & Tumor suppressor & TRIM27 & {$[52]$} \\
\hline miR-206 & & Inhibition of proliferation and metastasis & c-Met/AKT/mTOR Signaling Pathway & {$[143]$} \\
\hline miR-503-5p & Paclitaxel & Inhibition of tumor angiogenesis and growth & CD97-Mediated JAK2/STAT3 Pathway & {$[54]$} \\
\hline miR-30a-5p & & Inhibition of migration and invasion & SKP2, BCL9, and NOTCH1 & {$[144]$} \\
\hline miR-34a-5p & Cisplatin & Inhibition of proliferation and G1-phase cell cycle & PD-L1 & {$[145]$} \\
\hline
\end{tabular}


cells has recently been discovered [54]. MiR-503-5p inhibits the colony formation and metastasis of paclitaxel-resistant OC cells by inhibiting the CD97-mediated JAK2/STAT3 pathway. MiR-141/KLF12/Sp1/ survivin, as a new signaling axis, can enhance the drug resistance of $\mathrm{OC}$ and may be a potential target for the treatment of metastatic OC [55]. In addition, miR$200 \mathrm{c}$ has been proposed as a potential circulating biomarker in OC to predict the outcome of bevacizumab combined with standard chemotherapy over standard chemotherapy alone [56].

As a tumor suppressor, let-7g may be used to inhibit tumor progression and resistance to cisplatin chemotherapy in EOC [46]. Snail is a major regulator of epithelial-mesenchymal transition (EMT). Interestingly, the expression of the tumor suppressor gene let-7 was upregulated in snail knockout cells. These findings suggest that the Snail/Let-7 axis may be an appealing target for HGSOC therapy [57]. Unlike traditional tumor suppressors, miR-98-5p, as a member of the let-7 family, shows the greatest inhibitory effect on Dicer1 and is significantly upregulated in cisplatin-resistant EOC cell lines [58]. MiR-98-5p promotes chemo-resistance to cisplatin through a novel miR-98-5p/DICER1/miR-152 pathway. These results may provide new predictive and prognostic ideas for OC and aid in the design of new miRNA-based therapeutic strategies.

MiRNA detection methods are continually improved. Ongoing research aims to establish a drug delivery system that reduces their local accumulation, systemic toxicity, and side effects. The use of porous anti-miRNA nanoparticles for OC therapy is a new form of targeted therapy [59]. However, it is not clear how each miRNA can be applied to overcome drug resistance. In conclusion, the discovery of miRNAs and their application in the pathophysiology of $\mathrm{OC}$ create unlimited possibilities for the transformation of miRNA scientific research into clinical applications.

\section{LncRNA}

Unlike miRNAs and other non-coding transcripts, lncRNAs are complex and large, and their ability to regulate genes in almost all transition states indicates their potential [60] (Table 3). Abnormal expression levels of these lncRNAs can be detected in body fluids and tumor tissues. In EOC, hundreds of lncRNAs are differentially expressed compared with benign and normal control tissues [61]. LncRNAs exhibit a significant association with disease-free survival (DFS) and overall survival (OS) clinical outcomes, both individually and as part of molecular

Table 3 Molecular function of IncRNA in OC

\begin{tabular}{|c|c|c|c|c|}
\hline LncRNA & Adjust & Resistance against & Function & Target/pathway \\
\hline HOTAIR & $\uparrow$ & Cisplatin & Correlates with DNA damage response and senescence & $\begin{array}{l}\text { NF-kB [70]; } \\
\text { HOXA7 [146]; } \\
\text { miR-200c [147]; } \\
\text { P65, caspase 3/9 [148]; } \\
\text { MMP9, MMP3, E-cadherin, vimentin, snail [69]; } \\
\text { Wnt/ } \beta \text {-catenin [149]; }\end{array}$ \\
\hline $\mathrm{H} 19$ & $\uparrow$ & Cisplatin & Promotion of cell migration and invasion & $\begin{array}{l}\text { IGF2 [79]; } \\
\text { EZH2, P21, PTEN [150]; } \\
\text { miR-370-3p [151]; } \\
\text { let-7 [80]; } \\
\text { miR-370-3p-TGF-beta [151]; }\end{array}$ \\
\hline MALAT1 & $\uparrow$ & Cisplatin & Promotion of cell proliferation, migration, and invasion & $\begin{array}{l}\text { Notch1 [76]; } \\
\text { miR-200c [90]; } \\
\text { PI3K/AKT pathway [77]; }\end{array}$ \\
\hline MEG3 & $\downarrow$ & Cisplatin & Tumor suppressor & $\begin{array}{l}\text { EMT [152]; } \\
\text { miR-214 [86]; }\end{array}$ \\
\hline UCA1 & $\uparrow$ & Paclitaxel Cisplatin & Apoptosis; drug effluent system & miR-143/FOSL2 pathway [153]; \\
\hline XIST & $\uparrow$ & Cisplatin & Promotion of cell proliferation, migration, and invasion & hsa-miR-214-3p [93]; \\
\hline BC200 & $\downarrow$ & Carboplatin & Tumor suppressor & $\begin{array}{l}\text { Inhibited cell proliferation and increased the } \\
\text { sensitivity of OC cells to carboplatin [154]; }\end{array}$ \\
\hline LSINCT5 & $\uparrow$ & Paclitaxel & Promotion of cell proliferation, migration, and invasion & CXCL12/CXCR4 [155]; \\
\hline DNM3OS & $\uparrow$ & Cisplatin & Promotion of cell proliferation, migration, and invasion & EMT [152]; \\
\hline NEAT1 & $\uparrow$ & Paclitaxel & $\begin{array}{l}\text { Promotion of cell proliferation and metastasis } \\
\text { Inhibition of apoptosis }\end{array}$ & $\begin{array}{l}\operatorname{miR}-383-3 p[95] \\
\text { ZEB1 [81]; }\end{array}$ \\
\hline ANRIL & $\uparrow$ & Cisplatin & Promotion of cell proliferation and cell cycle progression & let-7a/HMGA2 [83]; \\
\hline GAS5 & $\downarrow$ & Platinum & Induction of apoptosis & cyclin D1, p21, APAF1 [85]; \\
\hline
\end{tabular}

$\downarrow$ : Downregulated; $\uparrow:$ Upregulated 
signatures $[62,63]$. By exploring and analyzing The Cancer Genome Atlas (TCGA) data, a 10-lncRNA prognostic signature can be used to assess the clinical outcomes of patients with HGSOC. Patients are classified into low-, medium-, and high-risk groups, with a significantly shortened OS and DFS in the high-risk group [63]. LncRNAs play roles in the pathogenesis and drug resistance to therapy in $\mathrm{OC}$ through various mechanisms, including aberrant lncRNA expression and single-nucleotide polymorphisms of functional lncRNAs. Recently, antisense and intergenic lncRNAs have been shown to regulate cell behavior in a variety of cancer types [64]. The expression of lncRNAs has been used to identify non-coding transcriptional markers associated with the prognosis of stage I EOC [65]. A signature composed of six different lncRNAs (RUNX1-IT1, MALAT1, H19, HOTAIRM1, LOC100190986, and AL132709.8) is significantly correlated with recurrence in OC [66]. Gene Ontology (GO) enrichment and Gene Set Enrichment Analysis (GSEA) identified five reliable lncRNAs (LINC00664, LINC00667, LINC01139, LINC01419 and LOC286437) that are involved in multiple mechanisms of OC. The five lncRNAs are independent risk factors for OC recurrence [67].

HOTAIR HOX antisense intergenic RNA (HOTAIR) was significantly increased in $44 \mathrm{OC}$ tissues compared with 14 normal ovary tissues [68]. HOTAIR levels were positively correlated with the FIGO stage, histological grade of the tumor, lymph node metastasis and reduced OS and DFS [69]. In OC, HOTAIR is upregulated and positively correlated with the transcription factor nuclear factor kappa B (NF-kB) levels [70]. The NF-kB-HOTAIR axis drives a positive-feedback loop cascade in the DNA damage response and contributes to cell senescence and chemotherapy resistance in OC. The knockdown of HOTAIR can increase $\mathrm{OC}$ sensitivity to cisplatin by inhibiting cisplatininduced autophagy [71]. The metastasis-promoting effect of HOTAIR is mediated by the regulation of the expression of many genes involved in EMT and cell metastasis, including matrix metalloproteinase 3(MMP3), MMP9, E-cadherin, vimentin and snail [69].

MALAT1 In the microarray analysis of lncRNAs, metastatic specific lung adenocarcinoma transcript 1 (MALAT1) was found to be significantly increased in OC tissues and cell lines [72, 73]. MALAT1 upregulation promotes the proliferation, migration, invasion, and metastasis of OC cells in vivo $[74,75]$. Survival analysis reveals that patients with increased MALAT1 expression have a poorer DFS time [73]. MALAT1 knockdown significantly reduced cisplatin resistance in $\mathrm{OC}$ by inhibiting the Notch1 signaling pathway [76]. MALAT1 also promotes metastasis and proliferation through the PI3K/AKT path- way in EOC [77]. Both HOTAIR and MALAT1 have been identified as potential therapeutic targets for restoring platinum sensitivity.

H19 The H19 gene is the first identified imprinted lncRNA with maternal expression. Together with a neighboring gene, insulin-like growth factor 2 (IGF2), H19 plays a key role in early pregnancy and normal menstrual cycles [78]. Recent studies have found that IGF2/H19 variants are significantly associated with genetic susceptibility to EOC in Han Chinese women [79]. As mentioned above, H19 is associated with OS and DFS in OC [66]. Interestingly, these events can be modulated by inhibiting let-7 and subsequently enhancing the expression of the target genes HMGA2, c-Myc, and IGF2BP, which promote metastasis [80].

Other $\ln c R N A s \quad$ High expression of nuclear paraspeckle assembly transcript 1 (NEAT1) has been observed in both OC cell lines and tumors. NEAT1 promotes drug resistance to paclitaxel by upregulating ZEB1 expression by sponging miR-194 [81]. Compared with non-cancer tissues, the expression of $A N R I L$ is significantly increased in EOC tissues, and increased ANRIL levels are associated with advanced FIGO stage, high histological grade, and poor OS [82]. Mechanistic investigations in vitro confirmed that silencing ANRIL promoted apoptosis and enhance the cisplatin sensitivity of OC cells by upregulating let-7a expression [83]. Furthermore, the upregulation of the lncRNAs long stress-induced non-coding transcript 5 (LSINCT5), colon cancer-associated transcript 2 (CCAT2), competing endogenous lncRNA 2 (CERNA2), $P V T 1$, and urothelial cancer-associated 1 (UCA1) have also been implicated in cancer-promoting mechanisms of OC [84].

In contrast, some lncRNAs are downregulated in OC. Reduced expression of brain cytoplasmic RNA 200 $(B C 200)$ and growth arrest-specific 5 (GAS5) has been observed in OC cells and tissues. GAS5 promotes OC tumorigenesis through its downstream effects on genes related to cell cycle progression, namely, P21, cyclin D1 and APAF1 [85]. LncRNA MEG3 is down expressed in OC. MEG3 upregulation can reduce the cisplatin resistance of OC cells by reducing EVS-mediated miR-214 [86]. In OC cells, lncRNA GAS5 inhibits the cell cycle and promotes apoptosis by reducing cyclin D1, p21 and APAF1 levels [85]. However, to date, few lncRNAs have been identified that could play key roles in the treatment of OC.

\section{LncRNA-miRNA interactions}

As mentioned above, lncRNAs mainly act as sponges that bind miRNAs and inhibit their functions. As a tumor 
suppressor gene, miR-129 has been reported to inhibit the proliferation and invasion of lung cancer and breast cancer [87, 88]. LncRNA SNHG12 is overexpressed in $\mathrm{OC}$, and its expression level shows a positive association with tumor size and FIGO stage. As a molecular sponge of miR-129, SNHG12 can directly bind to miR-129 and inhibit the function of miR-129, resulting in carcinogenesis [89]. MALAT1 also acts as a sponge for miR-200c and inhibits tumor growth through miR-506-dependent iASPP [90, 91]. LncRNA LINC01133 is downregulated in $\mathrm{OC}$ and acts as a negative regulator for miR-205, upregulating leucin-rich repeat kinase 2 (LRRK2) to inhibit OC development [92]. The lentivirus transfection of XIST into CAOV3 and OVCAR3 cell lines confirms that XIST can also directly act as a miRNA sponge to bind miR214-3p and inhibit its expression, thereby inhibiting EOC development and increasing cisplatin chemosensitivity [93].

Furthermore, lncRNAs have a synergistic effect on miRNAs. MEG3 mentioned above plays a role in targeting miR-214. HOTAIR promotes the proliferation and migration of OC cells via the miR-373 regulatory network [94]. NEAT1 promotes the infiltration and metastasis of OC cells by regulating the miR-382-3p/ROCK 1 axis [95]. LncRNA-TUSC7 is repressed in patients with OC, and reduced TUSC7 promotes invasion, proliferation and migration of OC cells through the miR-616-5p/ GSK3 $\beta / \beta$-catenin pathway [96]. These studies continue to improve the understanding of ncRNAs in OC. However, the extent to which these interactions are functionally relevant in cells is still a matter of debate.

\section{DNA methylation and histone modification}

The aberrant methylation of some oncogenes and tumor suppressor genes has been extensively investigated. The aberrant methylation of $\mathrm{CpG}$ islands in ovarian tumors is related to the regulation of the cell cycle, apoptosis, drug sensitivity, and the silencing of tumor suppressor genes. Demethylating agents can activate RNA transcription of silent endogenous retroviruses, stimulate antiviral interferon (IFN) signal transduction, and activate antitumor immune responses [97]. Thus, the regulation of gene expression by DNA methylation may play an important role in the gene competition between viruses and hosts.

The classic tumor suppressor gene, $B R C A 1$, was discovered in 1994 on chromosome 17q12-21. The hypermethylation of BRCA1 causes its expression to be decreased or deleted, inducing abnormal cell proliferation and affecting cell differentiation. The abnormal methylation of the dominant 5'UTR promoter leads to BRCA1 gene silencing, which is one of the causes of OC [98]. The abnormal methylation of $B R C A 1$ occurs in up to $15 \%$ in EOC [99], which is related to the initiation of $\mathrm{OC}$ and can therefore be used for targeted therapy. Poly-ADP ribose polymerase inhibitors (PARPis) are the first targeted drugs for OC [100]. PARPis prevent cells from repairing single-strand DNA damage, improve the 5-year survival of OC patients with BRCA1 mutations, and increase the sensitivity to platinum drugs due to the disruption of DNA repair. The benefits of PARPis are not limited to $B R C A$ mutation carriers but also extend to wild-type $B R C A$ carriers [101]. In patients with advanced OC who received firstline standard treatment that included bevacizumab and maintenance olaparib (a PARPi), a significant progression-free survival benefit was observed [102]. Therefore, the abnormal methylation of $B R C A 1$ is closely related to the initiation of $\mathrm{OC}$, targeted therapy, and prognosis.

Through DNA damage and cell cycle imbalance, the disruption of the histone methyltransferases EHMT1/2 (GLP/G9A) induces HGSOC cancer cell sensitivity to PARPis [103]. Ep-100 is a lytic peptide that specifically targets gonadotropin-releasing hormone receptors on cancer cells. Its combination with olaparib significantly increases the phosphorylation of histone $\mathrm{H} 2 \mathrm{AX}$ in $\mathrm{OC}$ cells, exacerbating DNA damage [104]. Thus, the combination of ep-100 and olaparib is a promising treatment strategy. All-trans retinoic acid (ATRA), a targeted drug used to treat hematological malignancies, can inhibit cell proliferation in telomerase reverse transcriptase (TERT)hypomethylated OC tissue types, and ATRA may be a new and effective individualized therapy [105]. Ubiquitin-specific protease 1 (USP1) stabilizes SNAIL by deubiquitination, thus promoting platinum resistance and OC cancer cell proliferation. The inhibition of USP1, in combination with platinum compounds, could be a successful strategy to improve platinum efficacy [106]. These studies demonstrate that there are other possible mechanisms in epigenetics that still need to be explored.

The antitumor efficacy of bromodomain and extraterminal motif protein inhibitors (BETis) has been demonstrated in numerous types of cancers. It has been estimated that members of the Switch/Sucrose Non-Fermentable (SWI/SNF) chromatin remodeling complex (including SMARCA4, ARID1A and PBRM1 subunits) are mutated in approximately $20 \%$ of all tumor types [107]. Aggressive OCs lacking SMARCA4 and SMARCA2 may be highly sensitive to BETis [108]. BETis show the highest level of antitumor activity when both SMARCA4 and SMARCA2 are mutated or lost. ARID1A is mutated in more than $50 \%$ of ovarian clear-cell carcinomas [109]. BRD2, a member of the BET family, specifically inhibits the proliferation of ARID1A-mutated cell lines [110]. There is an unexpected and lethal interaction between BRD2 deletion and ARID1A mutation. BETis lead to a reduction in the expression of multiple SWI/SNF members and may be a novel method for the 
treatment of ARID1A-mutated ovarian clear-cell carcinomas. Furthermore, BETis may enhance DNA damage induced by PARPis through homologous recombination [111].

To date, antitumor epigenetic drugs that have been marketed mainly consist of four categories. Two of the most classic epigenetic therapies investigated are DNMTis and HDACis [112] (Table 4). Histone demethylase inhibitors and histone methyltransferase EZH2 inhibitors are other antitumor drugs that have received much attention in the field of epigenetics. EZH2, a member of Polycomb Repressor Complex 2 (PRC2), is commonly involved in transcriptional repression and overexpressed in OC. Although many ongoing clinical trials are currently using EZH2 inhibitors, no one is studying the use of EZH2 inhibitors in OC patients [113].

DNMTis have been used for cancer immunotherapy, and representative nucleic acid analogs such as decitabine (DAC) and azacitidine (AZA). DNMTis have been approved for the treatment of acute myeloid leukemia (AML), chronic myelomonocytic leukemia (CMML), and myelodysplastic syndromes (MDS) and have been widely used in immunotherapeutic clinical trials of multiple cancers [114]. In OC cell lines, DNMTi treatment upregulates the expression of the antigen-processing and presentation molecules B2M, CALR, CD58, PSMB8, and PSMB9, demonstrating a possible mechanism for sensitizing ovarian tumors to immunotherapy [115]. By reducing the mRNA and protein levels of DNA methylase, ginsenoside $\mathrm{Rg} 3$ can promote the antitumor effects of $p 53, p 16$, and $h M L H-1$ in OC cells, inhibiting the migration and invasion of cancer cells, and promoting cell apoptosis [116]. In HGSOC, 5-hydroxymethylcytosine
(5-hmC) loss is an epigenetic hallmark that is associated with a poor overall survival rate, shorter time to relapse, and a reduced response to platinum-based chemotherapy [117]. DNMTi pretreatment restores 5-HMC loss and sensitivity to platinum chemotherapy. Recently, the DNMTi guadecitabine in combination with the PARPi talazoparib has been shown to increase the sensitivity of OC cells to PARPis, independent of the BRCA status [118]. The development of resistance and severe side effects are current therapeutic challenges for DNMTis that need to be overcome, and the hypermethylation of CpGs may be a novel mechanism of action for DNMTis. This finding provides a new idea for predicting the therapeutic efficacy and side effects of DNMTis [119].

HDACis are another promising new class of anticancer drugs that can induce cancer cell cycle arrest, differentiation, and cell death; reduce angiogenesis; and regulate the immune response [120]. Among the currently available HDACis, four have been tested in OC, including vorinostat, romidepsin, valproate, and PXD101. PAX8 is an EOC proto-oncogene. HDACis interfere with the transcription of $P A X 8$ and downstream factors by blocking the acetylation of histone H3K27 [121]. IKK inhibitors can improve the efficacy of HDACis in OC and that of other solid tumors by inhibiting IL-8 [122]. DHRS2 expression is decreased in OC, and high DHRS2 expression is correlated with a better prognosis. HDACis increase the mRNA and protein levels of DHRS2, suggesting that HDACis improve the prognosis of OC patients by upregulating the expression of DHRS2 [123]. As a single drug, HDACis effectively inhibit the growth and spread of ovarian tumors and synergize with platinum-based chemotherapy drugs, which shows a real

Table 4 Application of DNMTi and HDACi to OC treatment

\begin{tabular}{|c|c|c|}
\hline Drugs & Function & Reference \\
\hline \multicolumn{3}{|l|}{ DNMTi } \\
\hline \multirow[t]{2}{*}{ SGI-110 } & 1. Drug sensitizer used in combination with cisplatin & [156] \\
\hline & $\begin{array}{l}\text { 2. Enhances the immune recognition of tumor cells by regulating MHC class I and immu- } \\
\text { nomodulatory molecules in EOC cells, and is superior to AZA or DAC }\end{array}$ & [157] \\
\hline 5-Aza-2'-deoxycytidine (5-AZA-CdR) & Upregulate endogenous retrovirus (ERV) with G9Ai, synergistically induce antitumor & [158] \\
\hline 5-Azacytidine (5AZA-C) & $\begin{array}{l}\text { Induced the recruitment of activated }\left(\mathrm{IFNY}{ }^{+}\right) \mathrm{CD}^{+}{ }^{+} \mathrm{T} \text { cells, } \mathrm{CD} 8^{+} \mathrm{T} \text { cells and NK cells combining } \\
\text { with a-difluoromethylornithine (DFMO) }\end{array}$ & [159] \\
\hline \multicolumn{3}{|l|}{ HDACi } \\
\hline Entinostat (class I HDACi) & Synergistic effect with cisplatin in HGSOC & [160] \\
\hline Vorinostat & Inhibit tumor growth and prolong survival via targeting CD146 & {$[161]$} \\
\hline \multirow[t]{2}{*}{ Panobinostat } & 1. Synergistic effect with carboplatin in EOC & {$[162]$} \\
\hline & $\begin{array}{l}\text { 2. Reduce homologous recombination (HR) cyclin E-overexpression, as a means of enhancing } \\
\text { PARPi activity }\end{array}$ & [163] \\
\hline Thailandepsins & Inhibit cell viability and induce apoptosis & [164] \\
\hline Suberoylanilide hydroxamic acid (SAHA) & $\begin{array}{l}\text { Combined olaparib induced apoptosis and pH2AX expression more strongly to a greater } \\
\text { extent than either drug alone }\end{array}$ & {$[165]$} \\
\hline
\end{tabular}


potential for clinical success [124]. The efficacy of HDACis in the treatment of solid tumors remains uncertain. A hybrid HDAC inhibitor, the hybrid molecule RoxylZHC-84, has been developed. It greatly improves the limitations of traditional HDAC inhibitors in solid tumors by overcoming JAK1-STAT3-BCL2-mediated drug resistance and provides new ideas for the further research and development of antitumor drugs [125].

DNMTi and HDACi can increase the antitumor immunogenicity of cancer cells with beneficial effects on the immune microenvironment of ovarian tumors [126]. The combination of DNMTis and HDACis for the treatment of elderly patients with AML has been approved [127]. Dual inhibition may be a novel epigenetic therapy combination that can be used as a novel strategy for the treatment of OC.

\section{Conclusions}

Epigenetics is likely involved in the origin and progression of $\mathrm{OC}$ and will likely be an important treatment adjunct for OC. Epigenetics will likely provide an important tool for early molecular cancer screening and predictive markers for the selection of drug treatment protocols for high-risk patients. To date, most studies are in an early stage, and more intensive investigation is required. There is a limited understanding of OC disease progression; hence, the useful clinical application of epigenetics requires further investigation.

OC has an insidious onset, with multiple histological subtypes and complex molecular expression patterns. There are limitations to existing investigations in that reported study sample sizes are small, and the association of miRNA with disease occurrence lacks a causal relationship, with no identified specific OC biomarkers that can provide a direction for the analysis of miRNA. Furthermore, the lack of standardized protocols for sample collection and RNA extraction, as well as the less than ideal selection of individual patient differences, makes it difficult to compare reported results. LncRNAs are involved in the origin, invasion, and metastasis of OC. LncRNA function is multifaceted, with an array of complex cellular and molecular activities. Some lncRNAs show almost ubiquitous effects in $\mathrm{OC}$, and it will be interesting to consider whether most of them have specific functions and may influence the extent to which IncRNAs play a role in cancer. Abnormal DNA methylation and histone modification directly affect tumor progression and drug tolerance. DNA methylation is often used to compare the methylation status of specific genes in normal and OC cells. However, analysis of the genome-wide DNA methylation status is limited in that there is wide variability in sample size, tissue type, and analysis methodology. The analysis of histone-modified proteins remains in an early stage, and clinical trials of inhibitors are underway.

Understanding the molecular mechanisms underlying chemotherapeutic resistance is critical to treatment decisions and to the discovery of new anticancer drug targets. DNMTis and HDACis, or even a combination of the two, show great potential for the targeted treatment of OC. Currently, DNMTis are being evaluated in both preclinical and clinical settings, although cytotoxic side effects currently limit the clinical application of demethylating drugs. With the development of large-scale genome projects and sequencing technologies, such as the Encyclopaedia of DNA Elements (ENCODE) [128] and TCGA Project [129], our understanding of the mechanistic basis for treatment responses will become more important. Understanding the tumor tissue type, the gene sequence of an individual tumor, and the immune tumor microenvironment will allow the use of epigenetic drugs, immune regulators, targeted therapies, or a combination of these therapies to improve the clinical management of OC.

In the future, more research is needed to validate the biological mechanisms and clinical implications of tumor characterization at the molecular level, putting them into clinical practice. In addition, non-invasive approaches, such as diagnostic biomarkers in the blood or urine, are superior to invasive biopsy procedures. Immunotoxicity and other reactions will be important considerations when using epigenetic-based therapeutics. Thus, epigenetic studies have already added an additional layer of complexity to the understanding of $\mathrm{OC}$, although the mechanistic understanding of biological functions is only beginning to develop. The lack of appropriate detection systems and therapeutic targets for $\mathrm{OC}$ are still major challenges. The development of epigenetics has opened a new horizon to discover specific biomarkers and therapeutics that could ultimately change the future of $\mathrm{OC}$ diagnosis and treatment.

\section{Abbreviations}

OC: Ovarian cancer; EOC: Epithelial ovarian cancer; OSE: Ovarian surface epithelium; HGSOC: High-grade serous ovarian cancer; ncRNA: Non-coding RNA; miRNA: MicroRNA; IncRNA: Long non-coding RNA; DNMTi: DNA methylation inhibitor; HDACi: Histone deacetylase inhibitor; snRNA: Small nuclear RNA; snoRNA: Small nucleolar RNA; RNAi: RNA interference; sncRNA: Small noncoding RNA; siRNA: Short interfering RNA; bp: Base pairs; NF-kB: Nuclear factor kappa B; DNMTs: DNA methyltransferases; CpG: Cytosine-phosphate-guanine; HAT: Histone acetyltransferase; HDAC: Histone deacetylase; EMT: Epithelialmesenchymal transition; LRRK2: Leucin-rich repeat kinase 2; DFS: Disease-free survival; OS: Overall survival; TCGA: The Cancer Genome Atlas; GO: Gene Ontology; GSEA: Gene Set Enrichment Analysis; HOTAIR: HOX antisense intergenic RNA; MALAT1: Metastatic specific lung adenocarcinoma transcript 1; MMP3: Matrix metalloproteinase 3; IGF2: Insulin-like growth factor 2; NEAT1: Nuclear paraspeckle assembly transcript 1; LSINCT5: Long stress-induced non-coding transcript 5; CCAT2: Colon cancer-associated transcript 2; CERNA2: Competing endogenous InCRNA 2; UCA1: Urothelial cancer-associated 1; BC200: Brain cytoplasmic RNA 200; GAS5: Growth arrest-specific 5; IFN: Interferon; PARPI: PARP inhibitor; DAC: Decitabine; AZA: Azacitidine; AML: Acute myeloid 
leukemia; CMML: Chronic myelomonocytic leukemia; MDS: Myelodysplastic syndrome; 5-AZA-CdR: 5-Aza-2'-deoxycytidine; ERV: Endogenous retrovirus; 5AZA-C: 5-Azacytidine; DFMO: Difluoromethylornithine; HR: Homologous recombination; SAHA: Suberoylanilide hydroxamic acid; H3K27me3: Histone H3 lysine 27 trimethylation; ATRA: All-trans retinoic acid; TERT:Telomerase reverse transcriptase; USP1: Ubiquitin-specific protease 1; ENCODE: Encyclopaedia of DNA Elements.

\section{Acknowledgements}

Not applicable.

\section{Authors' contributions}

WX: conceptualization, writing - original draft, methodology, software. HS: resources, formal analysis. FL: validation, data curation. XL and ZW: writingreview and editing. XW: supervision, project administration, funding acquisition. All authors read and approved the final manuscript.

\section{Funding}

This work was supported by the National Natural Science Foundation of China (Grant Numbers 81930064, 81874103 and 81872117).

\section{Availability of data and materials}

Not applicable.

\section{Declarations}

\section{Ethics approval and consent to participate}

Not applicable.

\section{Consent for publication}

Not applicable.

\section{Competing interests}

The authors declare that they have no competing interests.

\section{Author details}

'Department of Obstetrics and Gynecology, Shanghai Jiao Tong University School of Medicine Xinhua Hospital, 1665 Kongjiang Road, Yangpu District, Shanghai, China. ${ }^{2}$ Department of Gynecology, Shanghai First Maternity and Infant Hospital, Tongji University School of Medicine, Shanghai, China.

\section{Received: 29 May 2021 Accepted: 3 Auqust 2021}

Published online: 17 August 2021

\section{References}

1. Siegel RL, Miller KD, Jemal A. Cancer statistics, 2019. CA Cancer J Clin. 2019;69(1):7-34.

2. Jelovac $D$, Armstrong DK. Recent progress in the diagnosis and treatment of ovarian cancer. CA Cancer J Clin. 2011;61 (3):183-203.

3. Bu H, Chen J, Li Q, Hou J, Wei Y, Yang X, et al. BRCA mutation frequency and clinical features of ovarian cancer patients: a report from a Chinese study group. J Obstet Gynaecol Res. 2019;45(11):2267-74.

4. Klotz DM, Wimberger P. Cells of origin of ovarian cancer: ovarian surface epithelium or fallopian tube? Arch Gynecol Obstet. 2017;296(6):1055-62.

5. Karnezis AN, Cho KR, Gilks CB, Pearce CL, Huntsman DG. The disparate origins of ovarian cancers: pathogenesis and prevention strategies. Nat Rev Cancer. 2017;17(1):65-74.

6. McCluggage W. Morphological subtypes of ovarian carcinoma: a review with emphasis on new developments and pathogenesis. Pathology. 2011:43(5):420-32.

7. Ivanova V, Dikov T, Dimitrova N. Histologic subtypes of ovarian carcinoma: selected diagnostic and classification problems in Bulgaria: is low hospital volume an issue? Tumori. 2017;103(2):148-54.

8. Chen VW, Ruiz B, Killeen JL, Coté TR, Wu XC, Correa CN. Pathology and classification of ovarian tumors. Cancer. 2003;97(10 Suppl):2631-42.
9. Crum CP, Drapkin R, Miron A, Ince TA, Muto M, Kindelberger DW, et al. The distal fallopian tube: a new model for pelvic serous carcinogenesis. Curr Opin Obstet Gynecol. 2007;19(1):3-9.

10. Pearce CL, Templeman C, Rossing MA, Lee A, Near AM, Webb PM, et al. Association between endometriosis and risk of histological subtypes of ovarian cancer: a pooled analysis of case-control studies. Lancet Oncol. 2012;13(4):385-94.

11. Gerlinger M, Swanton C. How Darwinian models inform therapeutic failure initiated by clonal heterogeneity in cancer medicine. $\mathrm{Br} J \mathrm{Cancer}$. 2010;103(8):1139-43.

12. Vella N, Aiello M, Russo AE, Scalisi A, Spandidos DA, Toffoli G, et al. "Genetic profiling" and ovarian cancer therapy (review). Mol Med Rep. 2011:4(5):771-7.

13. Sookram J, Zheng A, Linden KM, Morgan AB, Brown SA, Ostrovsky $O$. Epigenetic therapy can inhibit growth of ovarian cancer cells and reverse chemoresistant properties acquired from metastatic omentum. Int J Gynaecol Obstet. 2019;145(2):225-32.

14. Moore DS. Behavioral epigenetics. Wiley Interdiscip Rev Syst Biol Med. 2017;9(1):e1333.

15. Lyko F. The DNA methyltransferase family: a versatile toolkit for epigenetic regulation. Nat Rev Genet. 2018;19(2):81-92.

16. Li J, Liu C. Coding or noncoding, the converging concepts of RNAs. Front Genet. 2019;10:496.

17. Slack FJ, Chinnaiyan AM. The role of non-coding RNAs in oncology. Cell. 2019;179(5):1033-55.

18. Cheng CJ, Bahal R, Babar IA, Pincus Z, Barrera F, Liu C, et al. MicroRNA silencing for cancer therapy targeted to the tumour microenvironment. Nature. 2015;518(7537):107-10.

19. Calin GA, Sevignani C, Dumitru CD, Hyslop T, Noch E, Yendamuri S, et al. Human microRNA genes are frequently located at fragile sites and genomic regions involved in cancers. Proc Natl Acad Sci USA. 2004;101(9):2999-3004.

20. Balas MM, Johnson AM. Exploring the mechanisms behind long noncoding RNAs and cancer. Noncoding RNA Res. 2018;3(3):108-17.

21. Lorenzen J, Thum T. Long noncoding RNAs in kidney and cardiovascular diseases. Nat Rev Nephrol. 2016;12(6):360-73.

22. Gabory A, Ripoche M, Le Digarcher A, Watrin F, Ziyyat A, Forné T, et al. $\mathrm{H} 19$ acts as a trans regulator of the imprinted gene network controlling growth in mice. Development. 2009;136(20):3413-21.

23. Lee JT, Bartolomei MS. X-inactivation, imprinting, and long noncoding RNAs in health and disease. Cell. 2013;152(6):1308-23.

24. Li Q, Su Z, Xu X, Liu G, Song X, Wang R, et al. AS1DHRS4, a head-to-head natural antisense transcript, silences the DHRS4 gene cluster in cis and trans. Proc Natl Acad Sci USA. 2012;109(35):14110-5.

25. Grelet S, Link LA, Howley B, Obellianne C, Palanisamy V, Gangaraju VK, et al. A regulated PNUTS mRNA to IncRNA splice switch mediates EMT and tumour progression. Nat Cell Biol. 2017;19(9):1105-15.

26. Zhang J, Li Z, Liu L, Wang Q, Li S, Chen D, et al. Long noncoding RNA TSLNC8 is a tumor suppressor that inactivates the interleukin-6/STAT3 signaling pathway. Hepatology. 2018;67(1):171-87.

27. Hansen TB, Wiklund ED, Bramsen JB, Villadsen SB, Statham AL, Clark $\mathrm{SJ}$, et al. miRNA-dependent gene silencing involving Ago2-mediated cleavage of a circular antisense RNA. Embo J. 2011;30(21):4414-22.

28. Kunej T, Obsteter J, Pogacar Z, Horvat S, Calin G. The decalog of long non-coding RNA involvement in cancer diagnosis and monitoring. Crit Rev Clin Lab Sci. 2014;51(6):344-57.

29. Nervi C, De Marinis E, Codacci-Pisanelli G. Epigenetic treatment of solid tumours: a review of clinical trials. Clin Epigenet. 2015;7:127.

30. Pfeifer GP. Defining driver DNA methylation changes in human cancer. Int J Mol Sci. 2018;19(4):1166.

31. Van Tongelen A, Loriot A, De Smet C. Oncogenic roles of DNA hypomethylation through the activation of cancer-germline genes. Cancer Lett. 2017;396:130-7.

32. Jezek M, Green EM. Histone modifications and the maintenance of telomere integrity. Cells. 2019;8(2):199.

33. Cramer P. A tale of chromatin and transcription in 100 structures. Cell. 2014;159(5):985-94.

34. Baker SP, Grant PA. The proteasome: not just degrading anymore. Cell. 2005;123(3):361-3.

35. Trojer P, Reinberg D. Histone lysine demethylases and their impact on epigenetics. Cell. 2006;125(2):213-7. 
36. Soldi M, Bremang M, Bonaldi T. Biochemical systems approaches for the analysis of histone modification readout. Biochim Biophys Acta. 2014;1839(8):657-68.

37. Islas JF, Moreno-Cuevas JE. A microRNA perspective on cardiovascular development and diseases: an update. Int J Mol Sci. 2018;19(7):2075

38. Kian R, Moradi S, Ghorbian S. Role of components of microRNA machinery in carcinogenesis. Exp Oncol. 2018;40(1):2-9.

39. Bagnoli M, Canevari S, Califano D, Losito S, Maio MD, Raspagliesi F, et al. Development and validation of a microRNA-based signature (MiROvaR) to predict early relapse or progression of epithelial ovarian cancer: a cohort study. Lancet Oncol. 2016;17(8):1137-46.

40. Mandilaras $V$, Vernon $M$, Meryet-Figuière $M$, Karakasis $K$, Lambert $B$, Poulain $L$, et al. Updates and current challenges in microRNA research for personalized medicine in ovarian cancer. Expert Opin Biol Ther. 2017; 17(8):927-43.

41. Jia $Y$, Lin $R$, Jin $H$, Si L, Jian W, Yu Q, et al. MicroRNA-34 suppresses proliferation of human ovarian cancer cells by triggering autophagy and apoptosis and inhibits cell invasion by targeting Notch 1. Biochimie. 2019;160:193-9.

42. Su YY, Sun L, Guo ZR, Li JC, Bai TT, Cai XX, et al. Upregulated expression of serum exosomal miR-375 and miR-1307 enhance the diagnostic power of CA125 for ovarian cancer. J Ovarian Res. 2019;12(1):1-9.

43. Zhou B, Xu H, Xia M, Sun C, Li N, Guo E, et al. Overexpressed miR-9 promotes tumor metastasis via targeting E-cadherin in serous ovarian cancer. Front Med. 2017;11(2):214-22.

44. Wei C, Zhang X, He S, Liu B, Han H, Sun X. MicroRNA-219-5p inhibits the proliferation, migration, and invasion of epithelial ovarian cancer cells by targeting the Twist/Wnt/ $\beta$-catenin signaling pathway. Gene. 2017;637:25-32

45. Yu F, Yao H, Zhu P, Zhang X, Pan Q, Gong C, et al. let-7 regulates self renewal and tumorigenicity of breast cancer cells. Cell. 2007;131(6):1109-23.

46. Biamonte F, Santamaria G, Sacco A, Perrone FM, Di Cello A, Battaglia AM, et al. MicroRNA let-7g acts as tumor suppressor and predictive biomarker for chemoresistance in human epithelial ovarian cancer. Sci Rep. 2019;9(1):5668.

47. Busch B, Bley N, Müller S, Glaß M, Misiak D, Lederer M, et al. The oncogenic triangle of HMGA2, LIN28B and IGF2BP1 antagonizes tumor-suppressive actions of the let-7 family. Nucleic Acids Res. 2016:44(8):3845-64

48. Petrillo M, Zannoni G, Beltrame L, Martinelli E, DiFeo A, Paracchini L, et al. Identification of high-grade serous ovarian cancer miRNA species associated with survival and drug response in patients receiving neoadjuvant chemotherapy: a retrospective longitudinal analysis using matched tumor biopsies. Ann Oncol. 2016;27(4):625-34.

49. Qin X, Sun L, Wang J. Restoration of microRNA-708 sensitizes ovarian cancer cells to cisplatin via IGF2BP1/Akt pathway. Cell Biol Int. 2017;41(10):1110-8

50. LvT, Song K, Zhang L, Li W, Chen Y, Diao Y, et al. miRNA-34a decreases ovarian cancer cell proliferation and chemoresistance by targeting HDAC1. Biochem Cell Biol. 2018;96(5):663-71.

51. Jeong JY, Kang H, Kim TH, Kim G, Heo JH, Kwon AY, et al. MicroRNA-136 inhibits cancer stem cell activity and enhances the anti-tumor effect of paclitaxel against chemoresistant ovarian cancer cells by targeting Notch3. Cancer Lett. 2017:386:168-78.

52. Jiang J, Xie C, Liu Y, Shi Q, Chen Y. Up-regulation of miR-383-5p suppresses proliferation and enhances chemosensitivity in ovarian cancer cells by targeting TRIM27. Biomed Pharmacother. 2019;109:595-601.

53. Kanlikilicer P, Bayraktar R, Denizli M, Rashed MH, Ivan C, Aslan B, et al. Exosomal miRNA confers chemo resistance via targeting Cav1/pgp/M2-type macrophage axis in ovarian cancer. EBioMedicine. 2018;38:100-12.

54. Park GB, Kim D. MicroRNA-503-5p inhibits the CD97-mediated JAK2/ STAT3 pathway in metastatic or paclitaxel-resistant ovarian cancer cells. Neoplasia. 2019;21(2):206-15.

55. Mak CS, Yung MM, Hui LM, Leung LL, Liang R, Chen K, et al. MicroRNA-141 enhances anoikis resistance in metastatic progression of ovarian cancer through targeting KLF12/Sp1/survivin axis. Mol Cancer. 2017;16(1):11

56. Halvorsen AR, Kristensen G, Embleton A, Adusei C, Barretina-Ginesta $M P$, Beale $P$, et al. Evaluation of prognostic and predictive significance of circulating microRNAs in ovarian cancer patients. Dis Markers. 2017;2017:3098542.

57. Hojo N, Huisken AL, Wang H, Chirshev E, Kim NS, Nguyen SM, et al. Snail knockdown reverses stemness and inhibits tumour growth in ovarian cancer. Sci Rep. 2018;8(1):8704.

58. Wang Y, Bao W, Liu Y, Wang S, Xu S, Li X, et al. miR-98-5p contributes to cisplatin resistance in epithelial ovarian cancer by suppressing miR-152 biogenesis via targeting Dicer 1. Cell Death Dis. 2018;9(5):447.

59. Bertucci A, Kim K-H, Kang J, Zuidema JM, Lee SH, Kwon EJ, et al. Tumortargeting, microRNA-silencing porous silicon nanoparticles for ovarian cancer therapy. ACS Appl Mater Interfaces. 2019;11(27):23926-37.

60. Iyer M, Niknafs Y, Malik R, Singhal U, Sahu A, Hosono Y, et al. The landscape of long noncoding RNAs in the human transcriptome. Nat Genet. 2015;47(3):199-208.

61. Wang H, Fu Z, Dai C, Cao J, Liu X, Xu J, et al. LncRNAs expression profiling in normal ovary, benign ovarian cyst and malignant epithelial ovarian cancer. Sci Rep. 2016;6:38983.

62. Abildgaard C, Do Canto L, Steffensen K, Rogatto S. Long non-coding RNAs involved in resistance to chemotherapy in ovarian cancer. Front Oncol. 2019;9:1549.

63. Xu L, Wu Y, Che X, Zhao J, Wang F, Wang P, et al. Cox-LASSO analysis reveals a Ten-IncRNA signature to predict outcomes in patients with high-grade serous ovarian cancer. DNA Cell Biol. 2019;38(12):1519-28.

64. Ma J, Xiao Y, Tian B, Chen S, Zhang B, Wu J, et al. Long noncoding RNA Inc-ABCA12-3 promotes cell migration, invasion, and proliferation by regulating fibronectin 1 in esophageal squamous cell carcinoma. J Cell Biochem. 2020;121(2):1374-87.

65. Martini P, Paracchini L, Caratti G, Mello-Grand M, Fruscio R, Beltrame $L$, et al. IncRNAs as novel indicators of patients' prognosis in stage I epithelial ovarian cancer: a retrospective and multicentric study. Clin Cancer Res. 2017:23(9):2356-66

66. Yang K, Hou Y, Li A, Li Z, Wang W, Xie H, et al. Identification of a sixIncRNA signature associated with recurrence of ovarian cancer. Sci Rep. 2017;7(1):752

67. Chen Y, Bi F, An Y, Yang Q. Identification of pathological grade and prognosis-associated IncRNA for ovarian cancer. J Cell Biochem. 2019;120(9):14444-54.

68. Chang C, Tseng C, Lai M, Chiang A, Lo L, Chen C, et al. Genetic impacts on thermostability of onco-IncRNA HOTAIR during the development and progression of endometriosis. PLoS ONE. 2021;16(3):e0248168.

69. Qiu JJ, Lin YY, Ye LC, Ding JX, Feng WW, Jin HY, et al. Overexpression of long non-coding RNA HOTAIR predicts poor patient prognosis and promotes tumor metastasis in epithelial ovarian cancer. Gynecol Oncol. 2014;134(1):121-8.

70. Özeş AR, Miller DF, Özeş ON, Fang F, Liu Y, Matei D, et al. NF-kB-HOTAIR axis links DNA damage response, chemoresistance and cellular senescence in ovarian cancer. Oncogene. 2016;35(41):5350-61.

71. Yu Y, Zhang X, Tian H, Zhang Z, Tian Y. Knockdown of long non-coding RNA HOTAIR increases cisplatin sensitivity in ovarian cancer by inhibiting cisplatin-induced autophagy. J BUON. 2018;23(5):1396-401.

72. Liu S, Yang J, Cao D, Shen K. Identification of differentially expressed long non-coding RNAs in human ovarian cancer cells with different metastatic potentials. Cancer Biol Med. 2013;10(3):138-41.

73. Chen Q, Su Y, He X, Zhao W, Wu C, Zhang W, et al. Plasma long noncoding RNA MALAT1 is associated with distant metastasis in patients with epithelial ovarian cancer. Oncol Lett. 2016;12(2):1361-6.

74. Zhou Y, Xu X, Lv H, Wen Q, Li J, Tan L, et al. The Long Noncoding RNA MALAT-1 Is Highly Expressed in Ovarian Cancer and Induces Cell Growth and Migration. PLoS ONE. 2016;11(5):e0155250.

75. Zou A, Liu R, Wu X. Long non-coding RNA MALAT1 is up-regulated in ovarian cancer tissue and promotes SK-OV-3 cell proliferation and invasion. Neoplasma. 2016;63(6):865-72

76. Bai L, Wang A, Zhang Y, Xu X, Zhang X. Knockdown of MALAT1 enhances chemosensitivity of ovarian cancer cells to cisplatin through inhibiting the Notch1 signaling pathway. Exp Cell Res. 2018;366(2):161-71.

77. Jin Y, Feng SJ, Qiu S, Shao N, Zheng JH. LncRNA MALAT1 promotes proliferation and metastasis in epithelial ovarian cancer via the PI3K-AKT pathway. Eur Rev Med Pharmacol Sci. 2017;21(14):3176-84.

78. Ivanga M, Labrie Y, Calvo E, Belleau P, Martel C, Luu-The V, et al. Temporal analysis of E2 transcriptional induction of PTP and MKP and 
downregulation of IGF-I pathway key components in the mouse uterus. Physiol Genomics. 2007;29(1):13-23.

79. Zhang H-B, Zeng Y, Li T-L, Wang G. Correlation between polymorphisms in IGF2/H19 gene locus and epithelial ovarian cancer risk in Chinese population. Genomics. 2020;112(3):2510-5.

80. Yan L, Zhou J, Gao Y, Ghazal S, Lu L, Bellone S, et al. Regulation of tumor cell migration and invasion by the $\mathrm{H} 19 / \mathrm{let}-7$ axis is antagonized by metformin-induced DNA methylation. Oncogene. 2015;34(23):3076-84.

81. An J, Lv W, Zhang Y. LncRNA NEAT1 contributes to paclitaxel resistance of ovarian cancer cells by regulating ZEB1 expression via miR-194. Onco Targets Ther. 2017;10:5377-90.

82. Qiu J, Lin Y, Ding J, Feng W, Jin H, Hua K. Long non-coding RNA ANRIL predicts poor prognosis and promotes invasion/metastasis in serous ovarian cancer. Int J Oncol. 2015;46(6):2497-505.

83. Miao J-T, Gao J-H, Chen Y-Q, Chen H, Meng H-Y, Lou G. LncRNA ANRIL affects the sensitivity of ovarian cancer to cisplatin via regulation of let-7a/HMGA2 axis. Biosci Rep. 2019;39(7):BSR20182101.

84. Tripathi MK, Doxtater K, Keramatnia F, Zacheaus C, Yallapu MM, Jaggi $M$, et al. Role of IncRNAs in ovarian cancer: defining new biomarkers for therapeutic purposes. Drug Discov Today. 2018;23(9):1635-43.

85. Li J, Huang H, Li Y, Li L, Hou W, You Z. Decreased expression of long non-coding RNA GAS5 promotes cell proliferation, migration and invasion, and indicates a poor prognosis in ovarian cancer. Oncol Rep. 2016;36(6):3241-50

86. Zhang J, Liu J, Xu X, Li L. Curcumin suppresses cisplatin resistance development partly via modulating extracellular vesicle-mediated transfer of MEG3 and miR-214 in ovarian cancer. Cancer Chemother Pharmacol. 2017;79(3):479-87.

87. Setijono S, Park M, Kim G, Kim Y, Cho K, Song S. miR-218 and miR-129 regulate breast cancer progression by targeting Lamins. Biochem Biophys Res Commun. 2018;496(3):826-33.

88. Ma Z, Cai H, Zhang Y, Chang L, Cui Y. MiR-129-5p inhibits non-small cell lung cancer cell stemness and chemoresistance through targeting DLK1. Biochem Biophys Res Commun. 2017:490(2):309-16.

89. Sun D, Fan X. LncRNA SNHG12 accelerates the progression of ovarian cancer via absorbing miRNA-129 to upregulate SOX4. Eur Rev Med Pharmacol Sci. 2019;23(6):2345-52.

90. Li Q, Zhang C, Chen R, Xiong H, Qiu F, Liu S, et al. Disrupting MALAT1/ miR-200c sponge decreases invasion and migration in endometrioid endometrial carcinoma. Cancer Lett. 2016;383(1):28-40.

91. Lei R, Xue M, Zhang L, Lin Z. Long noncoding RNA MALAT1-regulated microRNA 506 modulates ovarian cancer growth by targeting iASPP. Onco Targets Ther. 2017;10:35-46.

92. Liu M, Shen C, Wang C. Long noncoding RNA LINC01133 confers tumor-suppressive functions in ovarian cancer by regulating leucine-rich repeat kinase 2 as an miR-205 sponge. Am J Pathol. 2019;189(11):2323-39.

93. Wang C, Qi S, Xie C, Li C, Wang P, Liu D. Upregulation of long noncoding RNA XIST has anticancer effects on epithelial ovarian cancer cells through inverse downregulation of hsa-miR-214-3p. J Gynecol Oncol. 2018;29(6):e99.

94. Zhang Z, Cheng J, Wu Y, Qiu J, Sun Y, Tong X. LncRNA HOTAIR controls the expression of Rab22a by sponging miR-373 in ovarian cancer. Mol Med Rep. 2016;14(3):2465-72.

95. Liu Y, Wang Y, Fu X, Lu Z. Long non-coding RNA NEAT1 promoted ovarian cancer cells' metastasis through regulation of miR-382-3p/ROCK1 axial. Cancer Sci. 2018;109(7):2188-98.

96. Zhu L, Li N. Downregulation of long noncoding RNA TUSC7 promoted cell growth, invasion and migration through sponging with miR616-5p/GSK3 $\beta$ pathway in ovarian cancer. Eur Rev Med Pharmacol Sci. 2020;24(13):7253-65.

97. Chiappinelli KB, Strissel PL, Desrichard A, Li H, Henke C, Akman B, et al. Inhibiting DNA Methylation Causes an Interferon Response in Cancer via dsRNA Including Endogenous Retroviruses. Cell. 2017;169(2):361.

98. Evans DGR, van Veen EM, Byers HJ, Wallace AJ, Ellingford JM, Beaman $G$, et al. A dominantly inherited 5'UTR variant causing methylationassociated silencing of BRCA1 as a cause of breast and ovarian cancer. Am J Hum Genet. 2018;103(2):213-20.

99. Eccles SA, Aboagye EO, Ali S, Anderson AS, Armes J, Berditchevski F, et al. Critical research gaps and translational priorities for the successful prevention and treatment of breast cancer. Breast Cancer Res. 2013;15(5):R92.

100. Dizon DS. PARP inhibitors for targeted treatment in ovarian cancer. Lancet. 2017;390(10106):1929-30.

101. Coleman RL, Oza AM, Lorusso D, Aghajanian C, Oaknin A, Dean A, et al. Rucaparib maintenance treatment for recurrent ovarian carcinoma after response to platinum therapy (ARIEL3): a randomised, double-blind, placebo-controlled, phase 3 trial. Lancet. 2017;390(10106):1949-61.

102. Ray-Coquard I, Pautier P, Pignata S, Pérol D, González-Martín A, Berger $\mathrm{R}$, et al. Olaparib plus bevacizumab as first-line maintenance in ovarian cancer. N Engl J Med. 2019;381(25):2416-28.

103. Watson ZL, Yamamoto TM, McMellen A, Kim H, Hughes $(J$, Wheeler $L$, et al. Histone methyltransferases EHMT1 and EHMT2 (GLP/G9A) maintain PARP inhibitor resistance in high-grade serous ovarian carcinoma. Clin Epigenet. 2019;11(1):165.

104. Ma S, Pradeep S, Villar-Prados A, Wen Y, Bayraktar E, Mangala LS, et al. GnRH-R-targeted lytic peptide sensitizes BRCA wild-type ovarian cancer to PARP inhibition. Mol Cancer Ther. 2019:18(5):969-79.

105. Losi L, Lauriola A, Tazzioli E, Gozzi G, Scurani L, D'Arca D, et al. Involvement of epigenetic modification of TERT promoter in response to all-trans retinoic acid in ovarian cancer cell lines. J Ovarian Res. 2019;12(1):62

106. Sonego M, Pellarin I, Costa A, Vinciguerra GLR, Coan M, Kraut A, et al. USP1 links platinum resistance to cancer cell dissemination by regulating Snail stability. Sci Adv. 2019;5(5):eaav3235.

107. Kadoch C, Crabtree G. Mammalian SWI/SNF chromatin remodeling complexes and cancer: mechanistic insights gained from human genomics. Sci Adv. 2015;1(5):e1500447.

108. Shorstova T, Marques M, Su J, Johnston J, Kleinman CL, Hamel N, et al. SWI/SNF-compromised cancers are susceptible to bromodomain inhibitors. Cancer Res. 2019:79(10):2761-74.

109. Jones S, Wang TL, Shih le M, Mao TL, Nakayama K, Roden R, et al. Frequent mutations of chromatin remodeling gene ARID1A in ovarian clear cell carcinoma. Science. 2010;330(6001):228-31.

110. Berns K, Caumanns JJ, Hijmans EM, Gennissen AMC, Severson TM, Evers $B$, et al. ARID1A mutation sensitizes most ovarian clear cell carcinomas to BET inhibitors. Oncogene. 2018;37(33):4611-25.

111. Yang L, Zhang Y, Shan W, Hu Z, Yuan J, Pi J, et al. Repression of BET activity sensitizes homologous recombination-proficient cancers to PARP inhibition. Sci Transl Med. 2017;9(400):eaal1645.

112. Chiappinelli KB, Zahnow CA, Ahuja N, Baylin SB. Combining epigenetic and immunotherapy to combat cancer. Cancer Res. 2016;76(7):1683-9.

113. Jones BA, Varambally S, Arend RC. Histone methyltransferase EZH2: a therapeutic target for ovarian cancer. Mol Cancer Ther. 2018;17(3):591-602.

114. Erdmann A, Halby L, Fahy J, Arimondo PB. Targeting DNA methylation with small molecules: what's next? J Med Chem. 2015;58(6):2569-83.

115. Siebenkäs C, Chiappinelli KB, Guzzetta AA, Sharma A, Jeschke J, Vatapalli $R$, et al. Inhibiting DNA methylation activates cancer testis antigens and expression of the antigen processing and presentation machinery in colon and ovarian cancer cells. PLoS ONE. 2017;12(6):e0179501.

116. Zhao L, Shou H, Chen L, Gao W, Fang C, Zhang P. Effects of ginsenoside Rg3 on epigenetic modification in ovarian cancer cells. Oncol Rep. 2019;41 (6):3209-18.

117. Tucker DW, Getchell CR, McCarthy ET, Ohman AW, Sasamoto N, Xu S, et al. Epigenetic reprogramming strategies to reverse global loss of 5-hydroxymethylcytosine, a prognostic factor for poor survival in highgrade serous ovarian cancer. Clin Cancer Res. 2018;24(6):1389-401.

118. Pulliam N, Fang F, Ozes A, Tang J, Adewuyi A, Keer H, et al. An effective epigenetic-PARP inhibitor combination therapy for breast and ovarian cancers independent of BRCA mutations. Clin Cancer Res. 2018;24(13):3163-75.

119. Abbotts R, Topper MJ, Biondi C, Fontaine D, Goswami R, Stojanovic L, et al. DNA methyltransferase inhibitors induce a BRCAness phenotype that sensitizes NSCLC to PARP inhibitor and ionizing radiation. Proc Natl Acad Sci USA. 2019;116(45):22609-18.

120. Eckschlager T, PIch J, Stiborova M, Hrabeta J. Histone deacetylase inhibitors as anticancer drugs. Int J Mol Sci. 2017;18(7):1414.

121. Shi K, Yin X, Cai MC, Yan Y, Jia C, Ma P, et al. PAX8 regulon in human ovarian cancer links lineage dependency with epigenetic vulnerability to HDAC inhibitors. Elife. 2019;8:e44306. 
122. Gatla HR, Zou Y, Uddin MM, Singha B, Bu P, Vancura A, et al. Histone deacetylase (HDAC) inhibition induces IKB kinase (IKK)-dependent interleukin-8/CXCL8 expression in ovarian cancer cells. J Biol Chem. 2017;292(12):5043-54

123. Han Y, Wang Z, Sun S, Zhang Z, Liu J, Jin X, et al. Decreased DHRS2 expression is associated with HDACi resistance and poor prognosis in ovarian cancer. Epigenetics. 2020;15:122-33.

124. Lapinska K, Housman G, Byler S, Heerboth S, Willbanks A, Oza A, et al. The effects of histone deacetylase inhibitor and calpain inhibitor combination therapies on ovarian cancer cells. Anticancer Res. 2016;36(11):5731-42.

125. Huang Z, Zhou W, Li Y, Cao M, Wang T, Ma Y, et al. Novel hybrid molecule overcomes the limited response of solid tumours to HDAC inhibitors via suppressing JAK1-STAT3-BCL2 signalling. Theranostics. 2018;8(18):4995-5011.

126. Moufarrij S, Srivastava A, Gomez S, Hadley M, Palmer E, Austin PT, et al. Combining DNMT and HDAC6 inhibitors increases anti-tumor immune signaling and decreases tumor burden in ovarian cancer. Sci Rep. 2020;10(1):3470

127. Blagitko-Dorfs N, Schlosser P, Greve G, Pfeifer D, Meier R, Baude A, et al. Combination treatment of acute myeloid leukemia cells with DNMT and HDAC inhibitors: predominant synergistic gene downregulation associated with gene body demethylation. Leukemia. 2019:33(4):945-56.

128. Davis CA, Hitz BC, Sloan CA, Chan ET, Davidson JM, Gabdank I, et al. The Encyclopedia of DNA elements (ENCODE): data portal update. Nucleic Acids Res. 2018;46(D1):D794-d801.

129. Tomczak K, Czerwińska P, Wiznerowicz M. The Cancer Genome Atlas (TCGA): an immeasurable source of knowledge. Contemp Oncol (Pozn). 2015;19(1a):A68-77.

130. Chen Z, Zhu J, Zhu Y, Wang J. MicroRNA-616 promotes the progression of ovarian cancer by targetingTIMP2. Oncol Rep. 2018;39(6):2960-8.

131. Wu X, Ruan $Y$, Jiang $H, X u$ C. MicroRNA-424 inhibits cell migration, invasion, and epithelial mesenchymal transition by downregulating doublecortin-like kinase 1 in ovarian clear cell carcinoma. Int J Biochem Cell Biol. 2017:85:66-74.

132. Kobayashi M, Sawada K, Nakamura K, Yoshimura A, Miyamoto M, Shimizu A, et al. Exosomal miR-1290 is a potential biomarker of highgrade serous ovarian carcinoma and can discriminate patients from those with malignancies of other histological types. J Ovarian Res. 2018;11(1):1.

133. Yoshimura A, Sawada K, Nakamura K, Kinose Y, Nakatsuka E, Kobayashi $M$, et al. Exosomal miR-99a-5p is elevated in sera of ovarian cancer patients and promotes cancer cell invasion by increasing fibronectin and vitronectin expression in neighboring peritoneal mesothelial cells. BMC Cancer. 2018;18(1):1065.

134. Ruan L, Xie Y, Liu F, Chen X. Serum miR-1181 and miR-4314 associated with ovarian cancer: MiRNA microarray data analysis for a pilot study. Eur J Obstet Gynecol Reprod Biol. 2018;222:31-8.

135. Hsu CY, Hsieh TH, Er TK, Chen HS, Tsai CC, Tsai EM. MiR381 regulates cell motility, growth and colony formation through PIK3CA in endometriosis associated clear cell and endometrioid ovarian cancer. Oncol Rep. 2018;40(6):3734-42

136. Yang B, Sun L, Liang L. MiRNA-802 suppresses proliferation and migration of epithelial ovarian cancer cells by targeting YWHAZ. J Ovarian Res. 2019;12(1):100

137. Li J, Shao W, Feng H. MiR-542-3p, a microRNA targeting CDK14, suppresses cell proliferation, invasiveness, and tumorigenesis of epithelial ovarian cancer. Biomed Pharmacother. 2019;110:850-6.

138. Kleemann $M$, Schneider H, Unger $K$, Sander $P$, Schneider EM, FischerPosovszky $P$, et al. MiR-744-5p inducing cell death by directly targeting HNRNPC and NFIX in ovarian cancer cells. Sci Rep. 2018;8(1):9020.

139. Li X, Chen W, Jin Y, Xue R, Su J, Mu Z, et al. miR-142-5p enhances cisplatin-induced apoptosis in ovarian cancer cells by targeting multiple anti-apoptotic genes. Biochem Pharmacol. 2019;161:98-112.

140. Niu L, Ni H, Hou Y, Du Q, Li H. miR-509-3p enhances platinum drug sensitivity in ovarian cancer. Gene. 2019;686:63-7.

141. Niu Q, Liu Z, Gao J, Wang Q. MiR-338-3p enhances ovarian cancer cell sensitivity to cisplatin by downregulating WNT2B. Yonsei Med J. 2019;60(12):1146-56.
142. Zhou Y, Wang M, Shuang T, Liu Y, Zhang Y, Shi C. MiR-1307 influences the chemotherapeutic sensitivity in ovarian cancer cells through the regulation of the $\mathrm{CIC}$ transcriptional repressor. Pathol Res Pract. 2019;215(10):152606.

143. Dai C, Xie Y, Zhuang X, Yuan Z. MiR-206 inhibits epithelial ovarian cancer cells growth and invasion via blocking c-Met/AKT/mTOR signaling pathway. Biomed Pharmacother. 2018;104:763-70.

144. Wang L, Zhao S, Yu M. Mechanism of low expression of miR-30a-5p on epithelial-mesenchymal transition and metastasis in ovarian cancer. DNA Cell Biol. 2019;38(4):341-51.

145. Zuo Y, Zheng W, Liu J, Tang Q, Wang SS, Yang XS. MiR-34a-5p/PD-L1 axis regulates cisplatin chemoresistance of ovarian cancer cells. Neoplasma. 2020;67(1):93-101.

146. Liu S, Lei H, Luo F, LiY, Xie L. The effect of IncRNA HOTAIR on chemoresistance of ovarian cancer through regulation of HOXA7. Biol Chem. 2018;399(5):485-97.

147. Yang C, Li H, Zhang T, Chu Y, Chen D, Zuo J. miR-200c overexpression inhibits the invasion and tumorigenicity of epithelial ovarian cancer cells by suppressing IncRNA HOTAIR in mice. J Cell Biochem. 2020;121(2):1514-23.

148. Tang Q, Lu M, Zhou H, Chen D, Liu L. Gambogic acid inhibits the growth of ovarian cancer tumors by regulating p65 activity. Oncol Lett. 2017;13(1):384-8

149. Li J, Yang S, Su N, Wang Y, Yu J, Qiu H, et al. Overexpression of long non-coding RNA HOTAIR leads to chemoresistance by activating the Wnt/ $\beta$-catenin pathway in human ovarian cancer. Tumour Biol. 2016:37(2):2057-65

150. Sajadpoor Z, Amini-Farsani Z, Teimori H, Shamsara M, Sangtarash $\mathrm{MH}$, Ghasemi-Dehkordi P, et al. Valproic acid promotes apoptosis and cisplatin sensitivity through downregulation of $\mathrm{H} 19$ noncoding RNA in ovarian A2780 cells. Appl Biochem Biotechnol. 2018;185(4):1132-44.

151. Li J, Huang Y, Deng X, Luo M, Wang X, Hu H, et al. Long noncoding RNA H19 promotes transforming growth factor- $\beta$-induced epithelialmesenchymal transition by acting as a competing endogenous RNA of miR-370-3p in ovarian cancer cells. Onco Targets Ther. 2018;11:427-40.

152. Mitra R, Chen X, Greenawalt EJ, Maulik U, Jiang W, Zhao Z, et al. Decoding critical long non-coding RNA in ovarian cancer epithelial-to-mesenchymal transition. Nat Commun. 2017:8(1):1604.

153. Li Z, Niu H, Qin Q, Yang S, Wang Q, Yu C, et al. IncRNA UCA1 mediates resistance to cisplatin by regulating the miR-143/FOSL2-signaling pathway in ovarian cancer. Mol Ther Nucleic Acids. 2019;17:92-101.

154. Wu DI, Wang T, Ren C, Liu L, Kong D, Jin X, et al. Downregulation of BC200 in ovarian cancer contributes to cancer cell proliferation and chemoresistance to carboplatin. Oncol Lett. 2016;11(2):1189-94.

155. Long X, Li L, Zhou Q, Wang H, Zou D, Wang D, et al. Long non-coding RNA LSINCT5 promotes ovarian cancer cell proliferation, migration and invasion by disrupting the CXCL12/CXCR4 signalling axis. Oncol Lett. 2018;15(5):7200-6.

156. Fang F, Munck J, Tang J, Taverna P, Wang Y, Miller DF, et al. The novel, small-molecule DNA methylation inhibitor SGI-110 as an ovarian cancer chemosensitizer. Clin Cancer Res. 2014:20(24):6504-16.

157. Srivastava P, Paluch BE, Matsuzaki J, James SR, Collamat-Lai G, Taverna P, et al. Immunomodulatory action of the DNA methyltransferase inhibitor SGI-110 in epithelial ovarian cancer cells and xenografts. Epigenetics. 2015;10(3):237-46.

158. Liu M, Thomas SL, DeWitt AK, Zhou W, Madaj ZB, Ohtani H, et al. Dual inhibition of DNA and histone methyltransferases increases viral mimicry in ovarian cancer cells. Cancer Res. 2018;78(20):5754-66.

159. Travers M, Brown SM, Dunworth M, Holbert CE, Wiehagen KR, Bachman KE, et al. DFMO and 5-azacytidine increase M1 macrophages in the tumor microenvironment of murine ovarian cancer. Cancer Res. 2019:79(13):3445-54

160. Bandolik JJ, Hamacher A, Schrenk C, Weishaupt R, Kassack MU. Class I-histone deacetylase (HDAC) inhibition is superior to pan-HDAC inhibition in modulating cisplatin potency in high grade serous ovarian cancer cell lines. Int J Mol Sci. 2019;20(12):3052.

161. Ma X, Wang J, Liu J, Mo Q, Yan X, Ma D, et al. Targeting CD146 in combination with vorinostat for the treatment of ovarian cancer cells. Oncol Lett. 2017:13(3):1681-7.

162. Helland Ø, Popa M, Bischof K, Gjertsen BT, McCormack E, Bjørge L. The HDACi panobinostat shows growth inhibition both in vitro and in a 
bioluminescent orthotopic surgical xenograft model of ovarian cancer. PLOS ONE. 2016;11(6):e0158208.

163. Wilson AJ, Sarfo-Kantanka K, Barrack T, Steck A, Saskowski J, Crispens MA, et al. Panobinostat sensitizes cyclin E high, homologous recombination-proficient ovarian cancer to olaparib. Gynecol Oncol. 2016;143(1):143-51.

164. Wilson AJ, Cheng Y-Q, Khabele D. Thailandepsins are new small molecule class I HDAC inhibitors with potent cytotoxic activity in ovarian cancer cells: a preclinical study of epigenetic ovarian cancer therapy. J Ovarian Res. 2012;5(1):12.
165. Suberoylanilide hydroxamic acid (SAHA) enhances olaparib activity by targeting homologous recombination DNA repair in ovarian cancer. Gynecol Oncol. 2014;133(3):599-606

\section{Publisher's Note}

Springer Nature remains neutral with regard to jurisdictional claims in published maps and institutional affiliations.
Ready to submit your research? Choose BMC and benefit from:

- fast, convenient online submission

- thorough peer review by experienced researchers in your field

- rapid publication on acceptance

- support for research data, including large and complex data types

- gold Open Access which fosters wider collaboration and increased citations

- maximum visibility for your research: over $100 \mathrm{M}$ website views per year

At BMC, research is always in progress.

Learn more biomedcentral.com/submissions 